Staff Working Paper/Document de travail du personnel 2020-15

Last updated: April 20, 2020

\title{
A Simple Method for Extracting the Probability of Default from American Put Option Prices
}

by Bo Young Chang ${ }^{1}$ and Greg Orosi ${ }^{2}$

${ }^{1}$ Funds Management and Banking Department Bank of Canada, Ottawa, Ontario, Canada K1A 0G9

bchang@bankofcanada.ca

${ }^{2}$ Department of Mathematics and Statistics American University of Sharjah, Sharjah, UAE

gorosi@ucalgary.ca

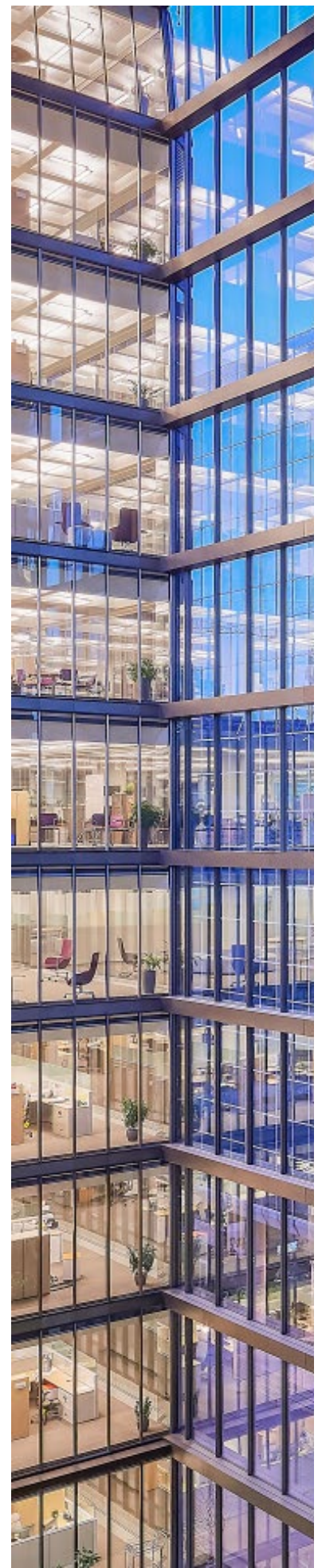

Bank of Canada staff working papers provide a forum for staff to publish work-in-progress research independently from the Bank's Governing Council. This research may support or challenge prevailing policy orthodoxy. Therefore, the views expressed in this paper are solely those of the authors and may differ from official Bank of Canada views. No responsibility for them should be attributed to the Bank. 


\section{Acknowledgements}

We would like to thank Nico Palesch for his excellent research assistance. 


\section{Abstract}

In this paper, we present a novel method to extract the risk-neutral probability of default of a firm from American put option prices. Building on the idea of a default corridor proposed in Carr and Wu (2011), we derive a parsimonious closed-form formula for American put option prices from which the probability of default can be inferred. The proposed method is easy to implement and helps overcome the main limitation of the method used in Carr and Wu (2011), which relies on the price of one deep-out-of-the-money put option. Our empirical results are based on seven large U.S. firms for the period 2002 to 2010. These results show that, in some cases, the option-implied probability of default can provide a more accurate estimate of default probability, compared to the estimates implied from credit default swap spreads.

Bank topics: Asset pricing; Financial markets; Market structure and pricing

JEL codes: G, G1, G13, G3, G33 


\section{Introduction}

We introduce a simple method for extracting the probability of a firm's default from the prices of American put options on the firm's stock. Building on the idea of a default corridor proposed by Carr and $\mathrm{Wu}$ (2011) (hereafter, referred to as CW) and the option-pricing method proposed by Orosi (2015), we first derive a new parsimonious closed-form pricing formula for American put options, which incorporates the possibility of default. We then calibrate the parameters of the proposed pricing formula to the observed put option prices in order to obtain an estimate of the probability of default.

An important insight of $\mathrm{CW}$ is that American put option values are not determined by the dynamics of the stock price within a certain low-strike region. These authors show that in this low-strike region, American put option prices are simply linear in strike and the slope of this linear segment is all we need to know to estimate a firm's default probability. Although theoretically appealing, CW's proposed implementation method has an important limitation in that the deep out-of-the-money options their method requires are not quoted in most cases. Our proposed method helps overcome this limitation.

Taylor et al. (2014) point out that there has been limited use of equity options to directly estimate the probability of default. Nonetheless, the advantage of extracting the option-implied probability of default (PD) is supported by the empirical tests of Camara et al. (2012). They find that employing European-style options to estimate PD is superior to the Moody's KMV model (Bohn et al., 2005) and other popular approaches. Chang and Orosi (2017) also develop a methodology for extracting the default probability from the prices of low-strike in-the-money call options. However, the calibration of a call option pricing formula to the observed prices poses a significant challenge because of the lack of available market quotes on these call options.

Alternatively, one can employ put options that are significantly more liquid at low strikes. However, to our knowledge, in the current literature, there is no straightforward method available for pricing and calibrating American-style put options on a defaultable stock, which poses a significant challenge for extracting the probability of default from these options. By deriving a parsimonious

pricing formula for American put options that incorporates the possibility of default, we provide a simple method for estimating a firm's probability of default from put options.

We test the empirical performance of our method by using data on the American put options and credit default swaps (CDS) of seven U.S. firms from various industries with varying credit qualities for the period 2002 to 2010. These firms are Altria, AT\&T, Citigroup, Fannie Mae, Ford, General Motors, and IBM. A comparison of the probability of default computed using our method with that implied from the CDS-spreads indicates that although the two estimates follow a similar trend, in some periods they can be significantly different. In particular, our analysis of the probability of default during the 2007-09 U.S. subprime mortgage crisis indicates that, for some firms, the CDS-implied probability of default may have been too low (Fannie Mae) or too high 
(Ford).

Our analysis of Fannie Mae leading up to its takeover by the U.S. government in 2008 indicates that the PD that is based on our method would have provided a better gauge of this firm's elevated default risk during the U.S. subprime mortgage crisis compared to that implied from the CDSspreads. A similar analysis of GM and Ford around their 2009 government bailouts also indicates that the CDS-implied PD being close to $100 \%$ for Ford was inconsistent with the firm's financial situation at the time. Our examples illustrate how our option-implied PD estimates can complement the information extracted from the CDS-spreads as our estimates can provide additional insights into a firm's default risk. A more comprehensive examination of the comparative performance of our method is beyond the scope of this paper, and is left for future research.

This paper is organized as follows. In section 1, we briefly describe the methodology introduced in Carr and Wu (2011). In section 2, we describe our methodology. In sections 3 and 4, we describe the data and the details of our model calibration. In section 5, we present the results of our empirical tests. We conclude in section 6 .

\section{Review of Carr and Wu (2011) methodology}

CW define a unit recovery claim (URC) as a digital contract. Essentially, the contract pays a unit of one dollar at default if the company defaults prior to the option expiry date and pays zero otherwise. The value of a URC is given by the following:

$$
U(T)=\int_{0}^{T} \lambda e^{-r s} e^{-\lambda s} d s=\lambda \frac{1-e^{-(r+\lambda) T}}{r+\lambda},
$$

where $r$ is the interest rate and $\lambda$ is the constant default arrival rate. Then, the risk-neutral probability of default, $P D$, can be computed from

$$
P D=1-e^{-\lambda T}
$$

CW also assume the presence of a default barrier $B$ and a default corridor $[A, B]$ that the stock price cannot enter. Moreover, it is assumed that if a company defaults, then its stock price defaults to the present value of $A$. Also, in case of default, the stock price only recovers to the present value of $A$. CW show that the price of an American put with a strike price that lies within the default barrier is given by the following:

$$
P_{1}(K, T)=K \cdot U(T)-A \cdot e^{-r T} \cdot P D .
$$

Hence, the value of an American put that struck within the default corridor is a linear function of $K$, and is independent of the pre-default stock price dynamics.

Under these assumptions, two American put options that have the same maturity $T$ and different strikes can be used to replicate a URC contract. If the strike prices both lie within the default barrier, then the relationship between a URC contract and the puts is given by the following: 


$$
U^{P}(T)=\frac{P_{A m}\left(K_{2}, T\right)-P_{A m}\left(K_{1}, T\right)}{K_{2}-K_{1}}
$$

where $P\left(K_{1}, T\right)$ and $P\left(K_{2}, T\right)$ are the prices of the put options and $K_{1}$ and $K_{2}$ are the strikes.

The relationship in equation (4) holds because of the property of the American options. If the company defaults before the option expiry date, then it is optimal to exercise both put options at the time of default. Conversely, if the company does not default, then the intrinsic value of both put options is zero. Therefore, the American put option spread in equation (4) has a unit payoff in the case of default and is zero otherwise.

If the additional assumption is made that the stock price drops to zero at the time of default (or equivalently $A=0$ ), then the relationship in equation (4) becomes

$$
U^{P}(T)=\frac{P_{A m}\left(K_{2}, T\right)}{K_{2}}
$$

if $K_{1}=0$ is used. Subsequently, $\lambda$ and $P D$ can be computed from equations (1) and (2). Hereafter, we will refer to this methodology of extracting $P D s$ from options as CW-based $P D$ s.

To test the empirical validity of the simple theoretical linkage between deep out-of-the-money American puts and the credit protection that they derive, CW propose a fairly crude implementation method of their formula. To identify a put option within the default corridor, they use two main criteria: (1) a low strike ( $\$ 5$ or less), and (2) a low delta (15\% or less). Although this implementation method provides an adequate approximation to test the general validity of their theoretical result, in practice, its applicability is highly limited due to the unavailability of such deep-out-of-the-money options in most cases.

This limitation is clearly demonstrated in $\langle$ Figure $\mathbf{1}>$, where we plot the daily prices of each stock in our sample, together with the daily lowest put strike price available. We find that with the exception of Ford, most stocks do not have the deep-out-of-the-money puts (e.g., strikes of less than $\$ 5$ as in $\mathrm{CW}$ ) that are required to estimate the probability of default when using the formula in equation (5).

\section{< Figure 1. Stock Price and Lowest Available Put Option Strike (2002-2010) >}

One way to deal with these limitations is to use smoothed (i.e., interpolated and extrapolated) option prices instead of the observed option prices. The use of smoothed option prices or smoothed implied volatilities is a standard technique in the literature that is known to work well in practice. However, our problem presents an additional challenge that is inherent in applying this general approach because the problem requires more robustness in its extrapolation beyond the lowest available strike, compared to other problems where it is sufficient to make a reasonable interpolation within the available strikes. To address this issue, instead of applying standard smoothing techniques to the option prices or implied volatilities, we propose to fit the available put option prices to a parsimonious option-pricing formula that is based on the idea of the default corridor introduced in CW. 


\section{Methodology}

To address the limitations outlined above, a suitable option-pricing model can be fitted to select put option prices. Essentially, employing such an approach overcomes the challenge of selecting appropriate strike prices. Furthermore, a default barrier and a lower bound can be incorporated as the model parameters. Finally, an option-pricing model can lessen the effect of misquotations.

An important insight of $\mathrm{CW}$ is that American put option values are not determined by the dynamics of the stock price and are also linear within a certain region. This idea is illustrated in $<$ Figure 2 $>$, which plots the American put prices for four different values of the volatility parameters for a jump-to-default geometric Brownian motion model as follows:

$$
\frac{d S_{t}}{S_{t}}=(r-d+\lambda) d t+\sigma S_{t} \cdot d W-d q
$$

where $d$ is the dividend rate, $\sigma$ is the volatility parameter, $W$ is the standard Brownian motion, and $d q$ is the infinitesimal jump process.

\section{$<$ Figure 2. Simulated American Put Option Prices $>$}

To price American puts whose underlying asset follows the price process in equation (6), we implement the method proposed by Milanaov et al. (2013). Their methodology relies on a simple binomial-tree representation of (6) that allows incorporating a positive equity recovery. Interestingly, the jump-to-default geometric Brownian motion model does not make an explicit assumption about a default barrier being in the form of a parameter. However, such a region exists because a stock price can only reach low strike levels in the case of default. Hence, a suitable model must be one that incorporates a linear function of strike prices within a certain region with a slope that equals $U(T)$.

Moreover, any model that incorporates default is capable of extracting the probability of default from a set of American put option prices with sufficiently low strikes. Although a stochastic volatility or multi-factor option-pricing model would provide a better fit to the observed option prices than the model considered in this study (assuming all these models incorporate default), at low strike levels the choice of model is irrelevant. Moreover, it is extremely challenging to calibrate and develop a pricing method for such a model.

Based on the preceding discussion, the following improvement can be made to the CW methodology. Instead of relying on equations (4) or (5), any model can be fitted to the available put option

prices if the model satisfies the following criteria: (i) it has zero value below a certain strike $K_{z e r o}$; (ii) it is a linear function for strikes that are less than $B$ but greater than $K_{z e r o}$; (iii) it is a convex and increasing function for strikes that are greater than $B$. Consequently, the price of an American put that is written on a defaultable stock is given by the following: 


$$
P(K, T)= \begin{cases}0 & \text { if } K \leq K_{\text {zero }} \\ P_{1}(K, T)=K \cdot U(T)-A \cdot e^{-r T} \cdot P D & \text { if } K_{\text {zero }} \leq K \leq B \\ P_{2}(K, T) & \text { if } B<K\end{cases}
$$

where

$$
K_{\text {zero }}=\frac{A \cdot e^{-r T} \cdot P D}{U(T)}
$$

and $P_{2}(K, T)$ is a convex and increasing function of $K$.

\subsection{Constructing Pricing Functions for American Puts on Non-Defaultable Stocks}

Assuming the absence of default, an analytic expression for American put options can be derived by following the framework presented in Orosi (2015). The main idea behind this approach is as follows. Essentially, it is possible to construct suitable pricing functions within a normalized space that is rotated counterclockwise by 45 degrees. Hence, first, the following transformations are applied to the strikes and put option prices:

$$
\begin{aligned}
& p=\frac{P(K, T)}{S} \\
& x=\frac{K}{S} .
\end{aligned}
$$

Then, by applying the transformations,

$$
\begin{aligned}
p^{*} & =\frac{x+p}{\sqrt{2}} \\
x^{*} & =\frac{x-p}{\sqrt{2}}
\end{aligned}
$$

one obtains $p^{*}$ and $x^{*}$, which represent the rotated values of $p$ and $k$, respectively. An example of the values of $p^{*}$ and $x^{*}$ obtained from market quotes is depicted in $<$ Figure $\mathbf{3}>$.

\section{$<$ Figure 3. Example of Market and Model Prices $>$}

Then, the function, $p^{*}$, with the positive parameter $G$

$$
p^{*}=G \frac{\left(x^{*}\right)^{2}}{\left(\frac{1}{\sqrt{2}}-x^{*}\right)}+x^{*}
$$

is convex and increasing. Moreover, the $p^{*}$ has a slope of 1 at $x^{*}=0$ and $p^{*} \rightarrow \infty$ as $x^{*} \rightarrow \frac{1}{\sqrt{2}}$. Moreover, the normalized put prices, $p$, can be obtained by rotating the above expression clockwise. This yields the following equation:

$$
\frac{x+p}{\sqrt{2}}=G \frac{\left(\frac{x-p}{\sqrt{2}}\right)^{2}}{\left(\frac{1}{\sqrt{2}}-\left(\frac{x-p}{\sqrt{2}}\right)\right)}+\frac{x-p}{\sqrt{2}}
$$


which has an analytic solution

$$
p=\frac{-\sqrt{2(G-1) x+x^{2}+1}+(G-1) x+1}{G-2} .
$$

Hence, the arbitrage-free American put option function for a fixed maturity is given by

$$
\begin{aligned}
& P(K, T)=S \cdot p \\
= & \frac{-S\left(\sqrt{2(G-1)\left(\frac{K}{S}\right)+\left(\frac{K}{S}\right)^{2}+1}+(G-1)\left(\frac{K}{S}\right)+1\right)}{G-2} .
\end{aligned}
$$

Furthermore, the function obtained from equation (9) satisfies the required conditions. Specifically, it has a value of 0 at $x=0$, a slope of 0 at $x=0$, and $p^{*} \rightarrow x-1$ as $x \rightarrow \infty$. Hence, the function $P(K, T)$ satisfies the no-arbitrage conditions of Merton (1973). Specifically, $P(K, T)$ is a convex and increasing function of $K, P(K, T) \leq K, \max (0, K-S) \leq P(K, T)$, where $S$ is the stock price,

$P(0, T)=0, \lim _{K \rightarrow \infty} \frac{P(K, T)}{K-S}=1$. Moreover, $\left.\frac{\partial P(K, T)}{\partial K}\right|_{K=0}=0$, which implies a zero probability of default.

\subsection{Constructing Pricing Functions for American Puts on Defaultable Stocks}

To modify equation (9) to incorporate default, one must start with the condition that $p$ and $P(K, T)$ have slopes of $U(T)$ at $x=0$ and $K=0$, respectively. Hence, the corresponding function in the space that is rotated counterclockwise by 45 degrees must be a slope of

$$
m=\frac{1+U(T)}{1-U(T)} .
$$

Incorporating this requirement yields

$$
\frac{x+p}{\sqrt{2}}=G \frac{\left(\frac{x-p}{\sqrt{2}}\right)^{2}}{\left(\frac{1}{\sqrt{2}}-\left(\frac{x-p}{\sqrt{2}}\right)\right)}+m \frac{x-p}{\sqrt{2}} .
$$

Although the put values can be obtained from the above in the case of $A=0$ and $B=0$ (the values of the default barrier), we require a suitable function for $P_{2}(K, T)$ in (7). To ensure that the first and second derivatives of $P_{1}(K, T)$ and $P_{2}(K, T)$ are continuous at $K=B$, we must have the following:

$$
\begin{aligned}
P_{2}(B, T) & =P_{1}(B, T)=U(T)\left(B-K_{\text {zero }}\right) \\
\left.\frac{\partial P_{2}(K, T)}{\partial K}\right|_{K=B} & =\left.\frac{\partial P_{1}(K, T)}{\partial K}\right|_{K=B}=U(T) .
\end{aligned}
$$

To achieve this, we first derive the value of $P_{1}(K, T)$ at $K=B$. The corresponding coordinates to $\left[B, U(T)\left(B-K_{z e r o}\right)\right]$ in the normalized and counterclockwise rotated space are given by the following:

$$
\left[x^{+}, y^{+}\right]=\left[\frac{\frac{B}{S}-\frac{U(T)\left(B-K_{z e r o}\right)}{S}}{\sqrt{2}}, \frac{\frac{B}{S}+\frac{U(T)\left(B-K_{z e r o}\right)}{S}}{\sqrt{2}}\right]
$$


Consequently, we must construct a function, $p_{2}^{*}$, such that $p_{2}^{*} \rightarrow \infty$ as $x^{*} \rightarrow \frac{1}{\sqrt{2}}-x^{+}$. An analytic solution can be obtained from

$$
\frac{x+p_{2}}{\sqrt{2}}=G \frac{\left(\frac{x-p_{2}}{\sqrt{2}}\right)^{2}}{\left(\frac{1}{\sqrt{2}}-x^{+}-\left(\frac{x-p}{\sqrt{2}}\right)\right)}+m \frac{x-p_{2}}{\sqrt{2}}
$$

and is given $b^{1}$ :

$$
\begin{aligned}
p_{2}= & \frac{-\sqrt{f(x)}-2 G x-2 x m-\sqrt{2} m x^{+}+m-\sqrt{2} x^{+}+1}{2(G-m-1)} \\
& \text { where } \\
f(x)= & -8 \sqrt{2} G x x^{+}+8 G x+4 x^{2}+4 \sqrt{2} x m x^{+} \\
& -4 x m+4 \sqrt{2} x x^{+}-4 x+2 m^{2}\left(x^{+}\right)^{2}+m^{2}-2 \sqrt{2} m^{2} x^{+} \\
& \left.+4 m\left(x^{+}\right)^{2}-4 \sqrt{2} m x^{+}+2 m+2\left(x^{+}\right)^{2}-2 \sqrt{2} x^{+}+1\right)
\end{aligned}
$$

Finally,

$$
P_{2}(K, T)=p_{2} \cdot S+U(T)\left(B-K_{z e r o}\right)
$$

Hence, the above formula and the expression in equation (7) can be fitted to put options by calibrating the following parameters: $\lambda, G, A$, and $B$. Finally $P D$ can be determined by using equations (4), (5), and (11).

\section{Data}

To provide an illustrative example of the empirical performance of our proposed method, we collect data on stock options (2002 to 2010) and CDS spreads (2004 to 2010) for the seven companies that were examined in Carr and $\mathrm{Wu}(2010){ }^{2}$ This sample includes companies from a wide spectrum of industries and with varied credit ratings, and a long period (9 years) covering times of various market conditions. The data on stock options are obtained from IVolatility. The data on CDS spreads are obtained from S\&P Capital IQ. We apply the following filters to the option data: (1) the bid price is greater than zero and (2) the open interest is greater than zero.

\section{$<$ Table 1. Summary of Option Data (2002-2010) >}

\footnotetext{
${ }^{1}$ A derivation using Mathematica software can be found at https://bit.ly/30PdxiM

${ }^{2}$ Carr and $\mathrm{Wu}$ (2010) uses eight companies in total, but our sample does not include Duke Energy Corporation since we do not have access to its CDS data.
} 


\section{Model calibration}

On each day, we fit two versions of the formula. In Model $1, \lambda, G, A$, and $B$ are the parameters that are extracted from option prices, whereas Model 2 assumes that $A$ is zero. For each trading day in the sample, the models are calibrated by minimizing the following objective function:

$$
\sqrt{\frac{1}{n} \sum_{i=1}^{n}\left(P_{i j}\left(\theta_{j}\right)-P_{i j}\right)^{2},}
$$

where $\theta_{j}$ represents the parameters for the $j^{t h}$ given trading day, the $\left\{P_{i j}\right\}_{i=1}^{n}$ are the interpolated option prices on the $j^{\text {th }}$ trading day (for all strikes and expiries), and the $P_{i j}\left(\theta_{j}\right)$-s are the option prices based on the model.

To estimate the probability of default for the 1-year horizon, we select the expiry that is closest to one year, with at least five put options and at least one out-of-the-money put option (i.e., strike $<$ stock price).

At the selected option expiry date, we fit a cubic Hermite spline to all of the available American put options plus one hypothetical put option at the strike price of zero whose price is also set to zero. Next, using the interpolant, we generate 21 uniformly distributed put option prices that have the same maturity date so that the minimum of the generated strike prices corresponds to zero and the maximum of the generated strike prices corresponds to the stock price.

As we pointed out earlier, we do not assume that the model in equation (7) produces put prices that provide a good fit for all strikes. However, for the options with low strike prices, the model prices should be sufficiently close to market prices.

\section{Empirical results}

We plot the daily estimates of the 1-year PD in $<$ Figure 4>. Our sample period 2002 to 2010 covers two periods of relatively high probability of default: the early 2000's following the dot-com bubble burst and the 2007-09 U.S. subprime crisis. Out of the seven companies in our sample, two companies experienced default events during the 2007-09 crisis. In September 2008, the U.S. government took over Fannie Mae and Freddie Mac by placing them into conservatorship of the Federal Housing Finance Agency (FHFA), triggering the payments on the credit default swaps that had been written on their bonds. GM filed for bankruptcy on June 1, 2009, despite having received financial assistance from the U.S. government earlier that year.

We plot the PDs that are estimated from the two models in $<$ Figure $4>$. The PDs from the two models are similar in trend, but the difference between the two PDs can be large, especially for the periods during which there was market stress. We find that Model 1, which allows for a positive equity recovery, gives a higher probability of default in general and its results are much less stable than those of Model 2 (e.g., for AT\&T and Fannie Mae in the early 2000s). In general, 
the relative instability of Model 1 makes it less desirable than Model 2, which assumes zero equity recovery.

\section{$<$ Figure 4. Estimates of a 1-Year Probability of Default (2002-2010) >}

\subsection{Comparison to the probability of default implied from credit default swaps}

We compare our PD estimates with the PDs implied from the 1-year credit default swaps in $<$ Figure 5 $>$. Since the CDS-implied PDs depend crucially on the assumption on the recovery rate to the bond holders, we report two CDS-implied PDs that are based on two bond-recoveryrate assumptions (30\% and 60\%). These assumptions are chosen to capture a reasonable range of bond-recovery-rates reported in Doshi, Elkamhi, and Ornthanalai (2018). However, to compare the CDS-implied PDs to the PDs of our proposed method, we simply assume a $40 \%$ bond recovery rate, which is a standard assumption used in the literature.

\section{$<$ Figure 5. Comparison to Probability of Default Implied from Credit Default Swaps (2002-2010)>}

We find that our PD estimates are comparable to the CDS-implied PDs, but the two PDs can deviate significantly during stress periods. For instance, we observe that differences in estimated PDs reached as high as 50 percentage points for Fannie Mae, Ford, and GM during the subprime crisis period.

In the case of Fannie Mae, the CDS spreads implied a very low possibility of default right up to the day when its takeover by the government was announced on September 6, 2008. Fannie Mae's low CDS-implied PD leading up to its demise in 2008 reflects investors' beliefs about an implicit guarantee that the government would not allow such an important institution to fail or to default on its debt. In contrast, the PD estimates from our model seem to have been a much better gauge of the firm's eventual fate, starting as early as late 2007. What these two PD estimates indicate is that investors were aware of the risk of a significant drop in Fannie Mae's stock price, but they also believed that there was little risk of default due to the implicit government guarantee. What the CDS-implied PD did not reflect is the fact that the standard CDS contracts considered the government's takeover of a firm to be equivalent to a bankruptcy because of the change in management control.

During the 2007-09 crisis, the U.S. government was also put in the position of providing financial bailouts to the country's largest three automakers (Chrysler, Ford, and GM). However, despite this support, Chrysler and GM declared bankruptcy in 2009. Ford did not require the use of bailout funds nor did it experience default. For both Ford and GM, we observe CDS-PDs close to 100\% between late 2008 and early 2009. This number is much higher than the PDs in our model, which hovered around $50 \%$. In the case of GM, it is not possible to conclude which estimate would have been more accurate ex-ante. However, the CDS-PD of close to $100 \%$ for Ford seems inconsistent 
with the fact that this company was in a much better shape financially than GM and it was widely known that Ford did not require assistance from the bailout fund.

These examples illustrate that it is often beneficial in practice to have more than one estimate for PDs that are extracted from two different markets that contain information on the market's perception of a firm's risk of default. Our method provides a relatively simple way to extract this information from stock option prices, which can then be used to complement the estimates obtained from the CDS-spreads.

\section{Conclusion}

Building on the idea of the default corridor proposed in Carr and Wu (2011), we introduce a simple method for extracting the probability of a firm's default from the prices of American put options. The proposed method is easy to implement and helps overcome the main limitation of the method used in Carr and Wu (2011), which relies on the price of one deep-out-of-the-money put option. Our empirical results on seven U.S. firms for the period 2002 to 2010 show that although the probabilities of default extracted from stock option prices show similar trends to the estimates implied from their credit default swaps, the two measures can be significantly different in some cases. In particular, our analysis of Fannie Mae, Ford, and GM for the 2007-09 financial crisis indicates that, in some cases, the CDS-implied probability of default may have been either too low (Fannie Mae) or too high (Ford). Our empirical results show that our option-implied estimates provide complementary information to the estimates extracted from the CDS-spreads.

$\ddagger$ Upon acceptance, the data files will be made publicly available with the permission of the Bank of Canada.

\section{References}

[1] Bohn, J., Arora, N., Korablev, I. (2005). Power and level validation of the EDF credit measure in the US market, Moody's KMV White Paper.

[2] Camara, A., Popova, I., and Simkins, B. (2012). A comparative study of the probability of default for global financial firms. Journal of Banking \& Finance, 36 (3), 717-732.

[3] Carr, P., and Wu, L. (2010). Stock Options and Credit Default Swaps: A Joint Framework for Valuation and Estimation. Journal of Financial Econometrics, 8 (4), 409-449.

[4] Carr, P., and Wu, L. (2011). A Simple Robust Link Between American Puts and Credit Protection. Review of Financial Studies. 24 (2), 473-505.

[5] Chang, B. Y., and Orosi, G. (2017). Equity Option Implied Probability of Default and Equity Recovery Rate. Journal of Futures Markets, 37 (6), 599-613. 
[6] Doshi, H., Elkamhi, R., and Ornthanalai, C. (2018). The Term Structure of Expected Recovery Rates, Journal of Financial and Quantitative Analysis, 53 (6), 2619-2661.

[7] Merton, R. C. (1973). Theory of Rational Option Pricing, The Bell Journal of Economics and Management Science, 4 (1), 141-183.

[8] Milanov, K., Kounchev, O., Fabozzi, F. J., Kim, Y. S., \& Rachev, S. T. (2013). A binomial-tree model for convertible bond pricing. The Journal of Fixed Income, 22 (3), 79.

[9] Orosi, G. (2015). An Interpolation-Based Approach to American Put Option Pricing. In: Abualrub T., Jarrah A., Kallel S., Sulieman H. (eds) Mathematics Across Contemporary Sciences. Springer Proceedings in Mathematics \& Statistics, vol 190. Springer, Cham.

[10] Taylor, S.J., Tzeng, C., and Widdicks M. (2014). Bankruptcy Probabilities Inferred from Option Prices, Journal of Derivatives, 22 (2), 8-31. 
$<$ Figure 1. Stock Price and Lowest Available Put Option Strike (2002-2010) >
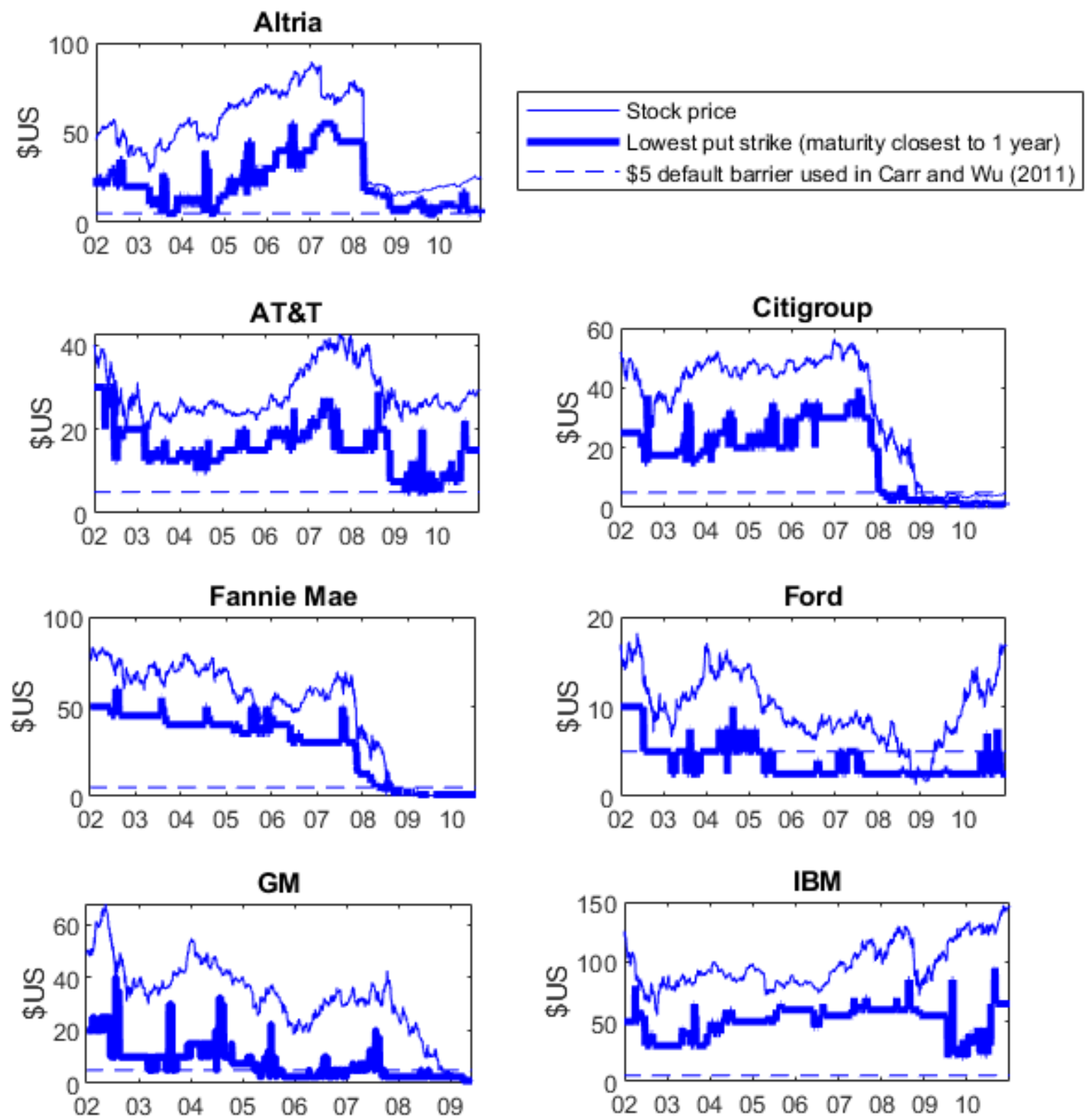

Note: We report the lowest put option strike with the time-to-maturity closest to one year on each day. Only the put options with positive open interest and positive bid price are considered. The "default barrier" introduced by Carr and Wu (2011) captures an extremely low level of stock price, which leads to a sudden drop in the stock price and the firm's default. Since Carr and Wu (2011) require the observed price of a put option, whose strike price is below the default barrier of $\$ 5$, as an input to estimate the probability of default, their method can only be used when such low-strike put option is observed in the market. 


\section{$<$ Figure 2. Simulated American Put Option Prices $>$}

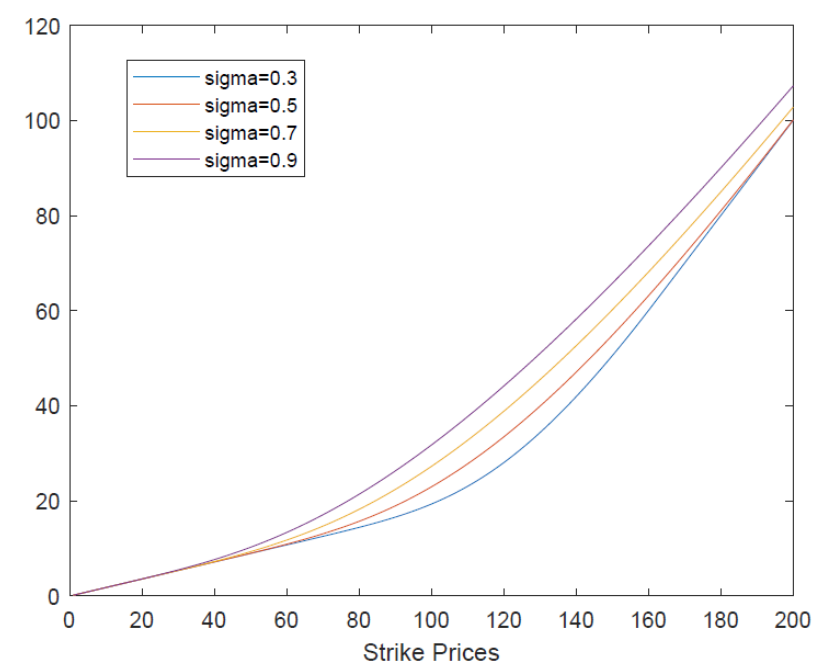

Note: It is assumed that the stock price follows a geometric Brownian motion with jump-to-default. The parameters used are the following: stock price $(\mathrm{S})=\$ 100$, riskfree rate $(\mathrm{r})=5 \%$, dividend yield $(\mathrm{d})=0 \%$, time-to-maturity $(\mathrm{T})=1$ year, $\lambda=0.4$, and $P D=30 \%$. 


\section{$<$ Figure 3. Example of Market and Model Prices $>$}
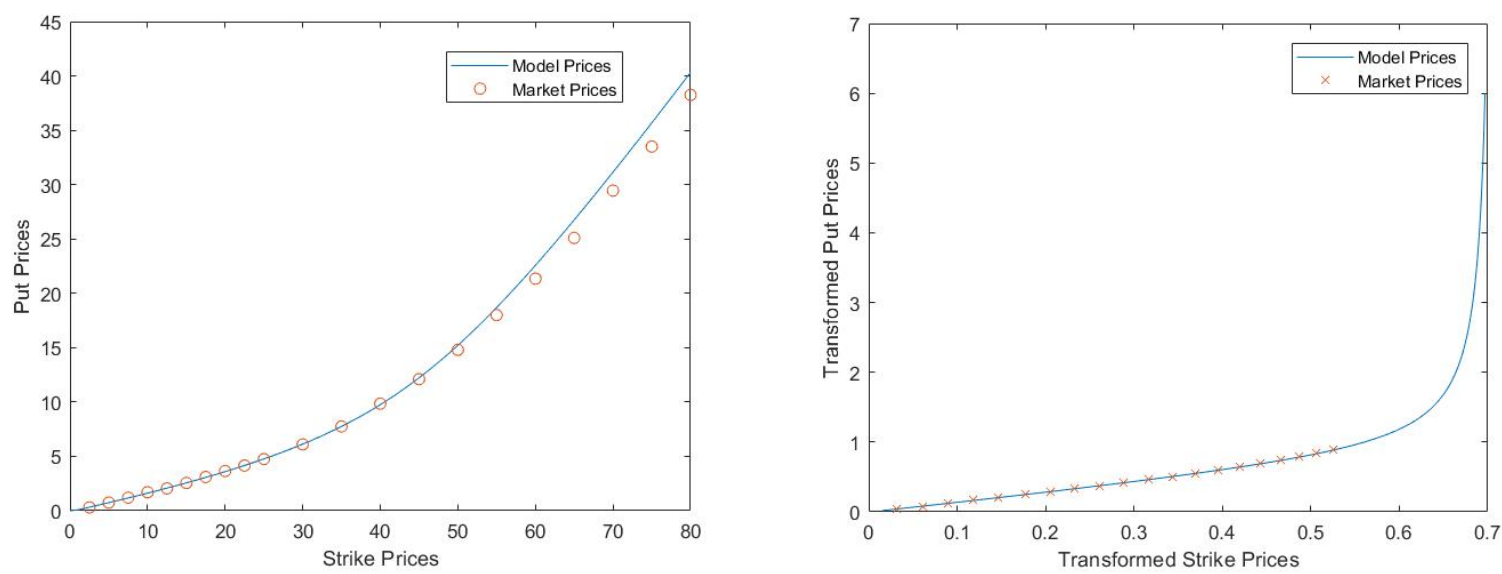

Note: In the panel on the left, we plot the American put options on Lehman Brothers' stock on March 19, 2008. In the panel on the right, we plot the market and model prices in the transformed space (normalized and rotated counterclockwise by 45 degrees). Options with strikes less than the stock price were used in the calibration. The parameters used are as follows: stock price $(\mathrm{S})=\$ 42.23$, time-to-maturity $(\mathrm{T})=0.83$ year, $A=0.5213, B=0.5213, \lambda=0.2119$, and $G=0.1091$. Fitting the model to the option prices gives a 1-year probability of default of $21.4 \%$. 
< Figure 4. Estimates of a 1-Year Probability of Default (2002-2010) >
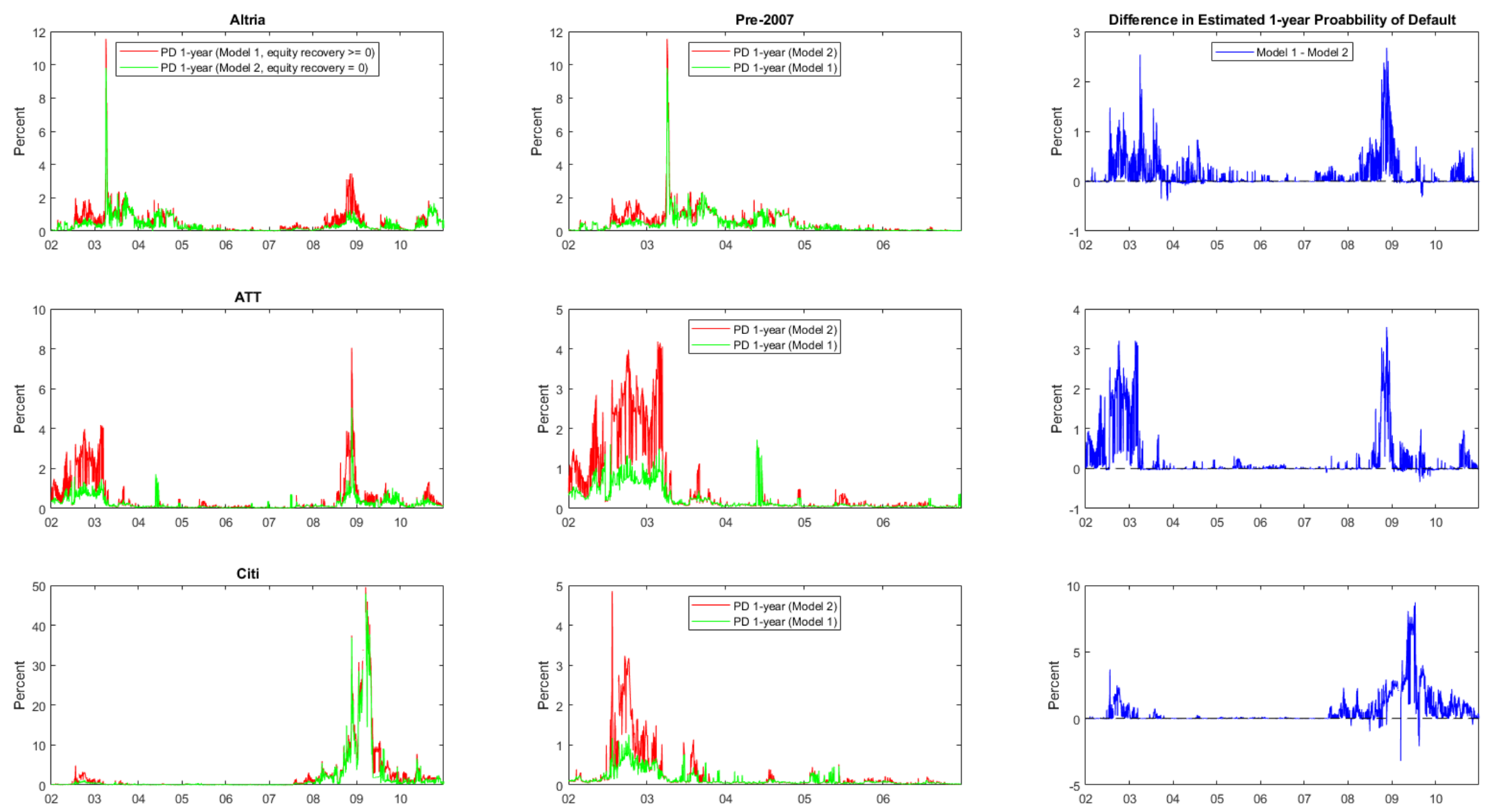

Note: PD - probability of default. Option data are obtained from IVolatility. 
< Figure 4 (continued). Estimates of a 1-Year Probability of Default (2002-2010) >
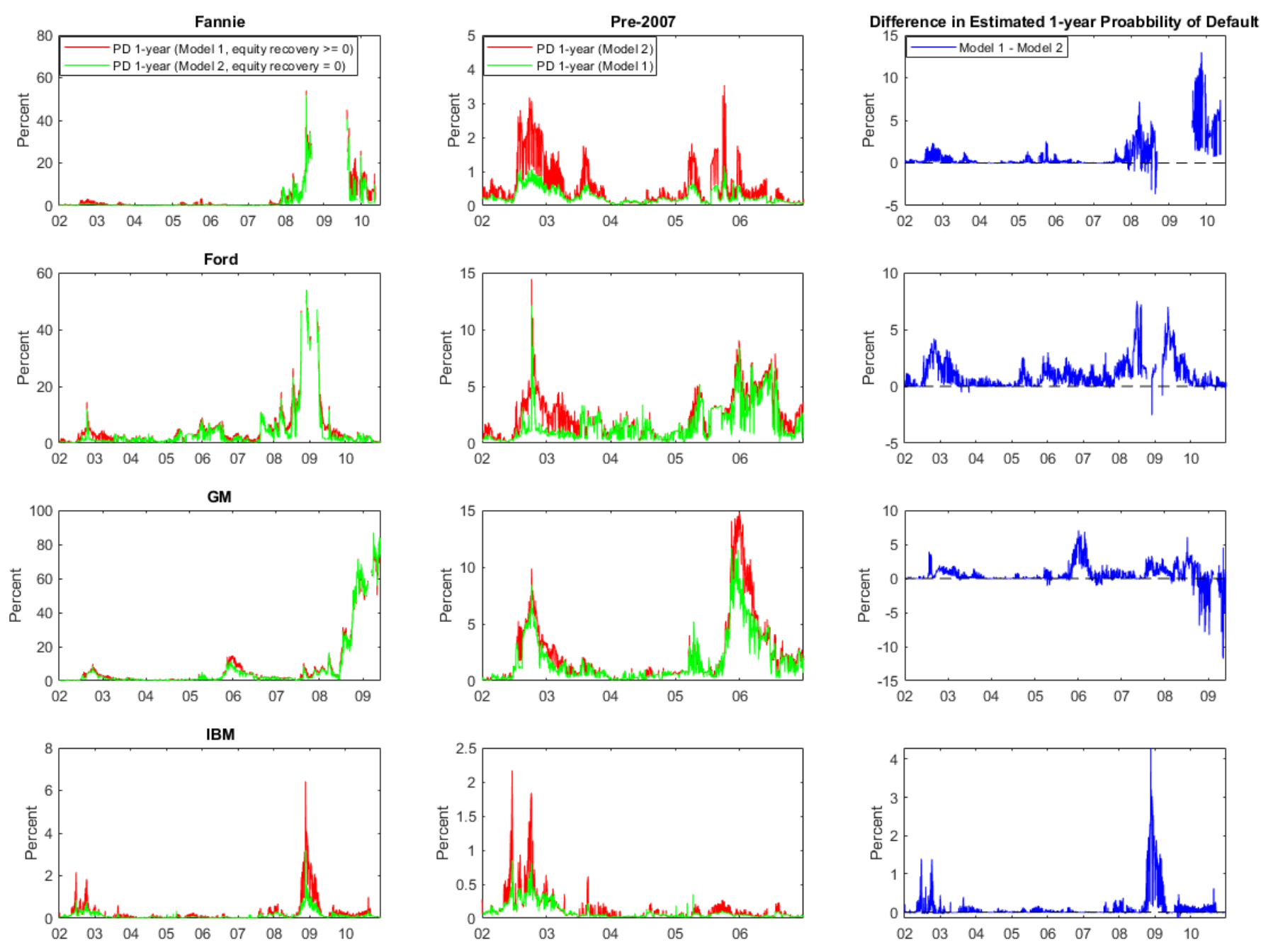
< Figure 5. Comparison to Probability of Default Implied from Credit Default Swaps (2002-2010) >
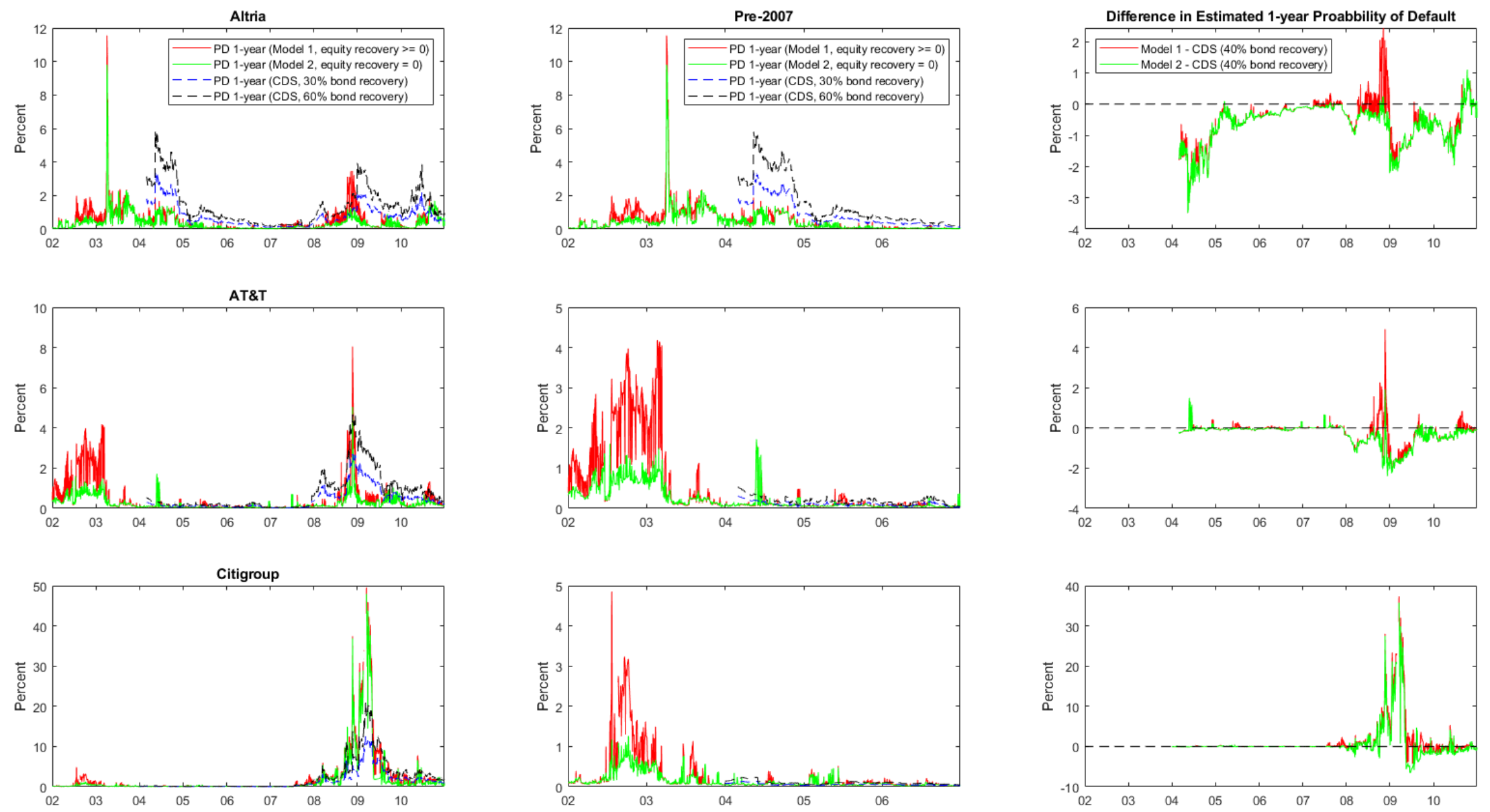

Note: PD - probability of default, CDS - credit default swap. Option data are obtained from IVolatility. CDS data are obtained from S\&P Capital IQ. 
< Figure 5 (continued). Comparison to Probability of Default Implied from Credit Default Swaps (2002-2010) >
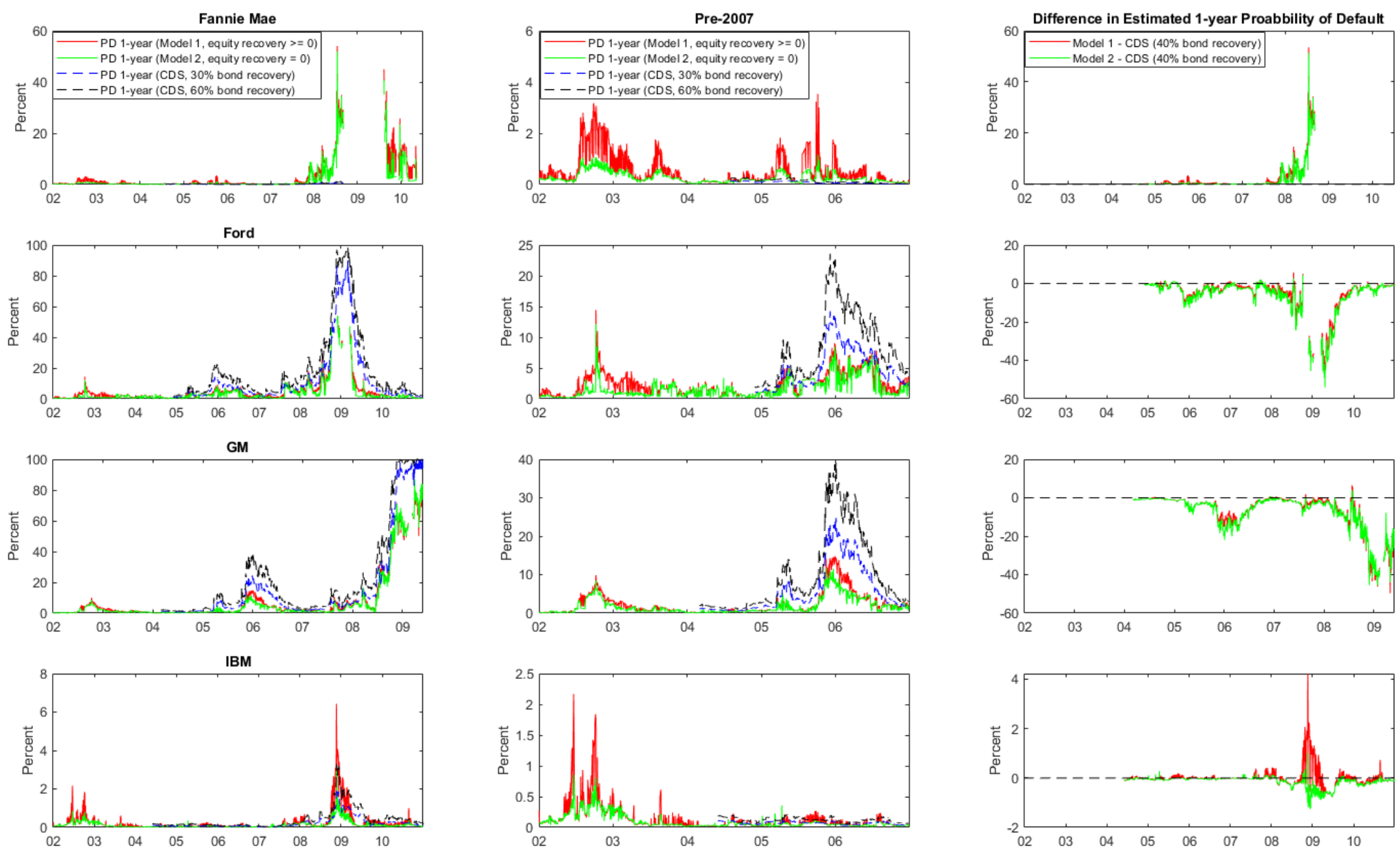
< Table 1. Summary of Option Data (2002-2011) >

\begin{tabular}{|c|c|c|c|c|c|c|c|c|c|c|}
\hline & \multicolumn{3}{|c|}{ All puts } & \multicolumn{3}{|c|}{ Out-of-the-money (OTM) puts } & \multicolumn{3}{|c|}{ Lowest daily put strike (\$) } & \multirow{2}{*}{$\begin{array}{l}\% \text { days with } \\
\text { no OTM puts }\end{array}$} \\
\hline & $\begin{array}{c}\text { Number of puts } \\
\text { (daily avg.) }\end{array}$ & $\begin{array}{l}\text { Avg. implied } \\
\text { volatility }\end{array}$ & $\begin{array}{c}\text { Avg. bid-ask } \\
\text { spread (\% of } \\
\text { mid-price) }\end{array}$ & $\begin{array}{l}\text { Number of puts } \\
\text { (daily avg.) }\end{array}$ & $\begin{array}{l}\text { Avg. implied } \\
\text { volatility }\end{array}$ & $\begin{array}{c}\text { Avg. bid-ask } \\
\text { spread (\% of } \\
\text { mid-price) }\end{array}$ & Average & Min. & Max. & \\
\hline Altria & 57 & 0.30 & $14 \%$ & 31 & 0.34 & $23 \%$ & 18.47 & 2.50 & 55.00 & $0 \%$ \\
\hline AT\&T & 50 & 0.31 & $12 \%$ & 23 & 0.34 & $22 \%$ & 13.10 & 2.50 & 20.00 & $0 \%$ \\
\hline Citigroup & 65 & 0.52 & $10 \%$ & 25 & 0.44 & $23 \%$ & 15.10 & 1.00 & 37.50 & $1 \%$ \\
\hline Fannie Mae & 51 & 0.66 & $9 \%$ & 21 & 0.50 & $18 \%$ & 27.61 & 1.00 & 50.00 & $14 \%$ \\
\hline Ford & 44 & 0.55 & $11 \%$ & 16 & 0.57 & $25 \%$ & 3.35 & 1.00 & 10.00 & $4 \%$ \\
\hline GM & 74 & 0.64 & $11 \%$ & 34 & 0.63 & $20 \%$ & 5.68 & 1.00 & 20.00 & $1 \%$ \\
\hline IBM & 77 & 0.30 & $11 \%$ & 38 & 0.34 & $19 \%$ & 44.33 & 20.00 & 80.00 & $0 \%$ \\
\hline
\end{tabular}

Note: Only options with positive open interest and positive bid prices are included in the summary. Source - IVolatility.com 